\title{
ANALYSIS OF INDOOR ALDEHYDES IN THE COMANDANTE FERRAZ ANTARCTIC STATION
}

http://dx.doi.org/10.4322/apa.2014.085

\author{
Érica Coelho Pagel ${ }^{1, *}$, , Sandra P. Beghi ${ }^{1}$, Cristina Engel de Alvarez ${ }^{1}$, Neyval Costa Reis Júnior ${ }^{1}$, \\ Paulo Wagnner P. Antunes ${ }^{1}$, Sérvio Túlio Cassini ${ }^{1}$, Jane M. Santos ${ }^{1}$ \\ 1Universidade Federal do Espírito Santo - UFES, Av. Fernando Ferrari, 514, Goiabeiras, CEP 29075-910, Vitória, ES, Brazil \\ *e-mail: erica.pagel@gmail.com
}

\begin{abstract}
The study of indoor air quality has recently increased since most of the time people are in closed spaces. A large contribution to the emission of indoor pollutants is originated from human activities and building processes. Volatile Organic Compounds, mainly from the aldehydes group are present in most parts of new flooring and furnishing, furthermore, these substances have adverse effects on human health. This study investigated the aldehyde concentration using passive samplers in many places of Comandante Ferraz Brazilian Antarctic Station. The results showed compounds like formaldehyde, acrolein, acetaldehyde and hexanaldehyde with significant concentration indoors, in that formaldehyde concentration in new rooms exceeded the guidelines of The World Health Organization. Therefore, these results show the need for monitoring these compounds as well as the study of the sources of emission.
\end{abstract}

Keywords: aldehydes, indoor air quality, passive sampling, building materials

\section{Introduction}

Over the last half-century there have been major changes in building materials, personal habits and consumer products used indoors: composite-wood, synthetic carpets, polymeric flooring, foam cushioning, plastic items, scented cleaning agents, time spent indoors, air- conditioning and others have become ubiquitous (Weschler, 2008). These new habits and new chemical substances in indoor spaces other than architectural typology can intensify low rates of air exchange and contribute significantly to indoor air quality of a building.

Studies have shown that building materials are responsible for about $40 \%$ of the level of emissions of indoor pollutants, with significant amounts of emission coming from Volatile Organic Compounds (VOCs) present in these materials (Missia et al., 2010). Among compounds, aldehydes are of particular interest due to their impact on health and because they are mainly domestic environment pollutants.

Most studies of aldehydes are related to formaldehyde, classified in Group 2A by the International Agency of
Research on Cancer due to its carcinogenicity. It has an effect on health depending on environment levels. The olfactory detection threshold is $60 \mu \mathrm{g} / \mathrm{m}^{3}$ and varies according to each person; it can cause headaches, nausea or dizziness. It can also cause mucous irritations as a result of exposure at levels from $10 \mu \mathrm{g} / \mathrm{m}^{3}$ and chronic exposure of formaldehyde can induce conjunctivitis, pharyngitis, laryngitis, bronchitis or coughing (Clarisse et al., 2003). The World Health Organization recommended an exposure limited to $100 \mu \mathrm{g} / \mathrm{m}^{3}$ for about 30 minutes to prevent long-term effects on human health including cancer (WHO, 2010). It is known that other specific aldehydes like acrolein and acetaldehyde also cause irritation of eyes, skin and mucous membranes of the human respiratory tract. The acetaldehyde, for example, has been classified as B2, as a likely human carcinogen of low carcinogenic hazard (Weng et al., 2009).

The purpose of our work is to identify and quantify VOCs of the aldehyde group inside Comandante Ferraz Antarctic Station located in Admiralty Bay, King George 
Island, South Shetlands archipelago. The results will evaluate the contribution of pollution sources from human activities and building materials, as Antarctica is a natural environment without the anthropogenic interference of urban centers. Moreover, a large time spent indoors at the Antarctica Station with probable indoor sources of emission is a motivation of studies related to health and Sick Building Syndrome (SBS).

\section{Materials and Methods}

The experiment was carried out from January $14^{\text {th }}$ to February $3^{\text {rd }}$ in the Comandante Ferraz Antarctic Station. The sampler spaces were selected because of their high usage with likely indoor pollution sources.

The study considered ten indoor spaces. Three spaces of general use: living room, library and gym. Three bedrooms: two for two people and the third being the Arsenal accommodation (twelve people). Four work spaces: kitchen, carpentry, "Ferrazão" and a space near the incinerator. The kitchen was located inside the main body of the station and the other workspaces were located outside the main body of the station, without a heating system, but with roof cover. In general, the mean indoor temperature of the spaces is $22{ }^{\circ} \mathrm{C}$ and the relatively humidity around $33 \%$. In the outside working area the mean temperature is $9^{\circ} \mathrm{C}$ and the relatively humidity, 26\%. The space distribution samplers were placed according to Figure 1.

Aldehydes were sampled using Radiello ${ }^{\star}$ Aldehydes Samplers (Fondazione Salvatore Maugeri, 2011). These are passive samplers that are impregnated cartridges with 2,4-dinitrophenyhydrazones adsorbent in a cylindrical body. The samplers were left about 3, 6 or 7 days according to manufacturer's recommendation and the potential pollution of space. A total of 16 samplers and four blanks (samplers that were not exposed to the environment in order to detect back noise or transport contamination) were placed. The samplers were exposed at a standard height of $1.5 \mathrm{~m}$ (The European Standard, 2006), which is the medium height of human breathing, and when possible in the space centre (Figure 2).

A questionnaire was also made for each space, summarizing the present building material, the human activities during the sampling and other pollution sources. After exposure the cartridge was set in a specific and identified glass tube and stored in the refrigerator (below $4^{\circ} \mathrm{C}$ ) in the station to be transported in the same conditions to Brazil. In Brazil the adsorbent was put into a tube with $2 \mathrm{~mL}$ of acetonitrile, and then it was closed and sonicated for 30 minutes. The final solution of each sampler was then

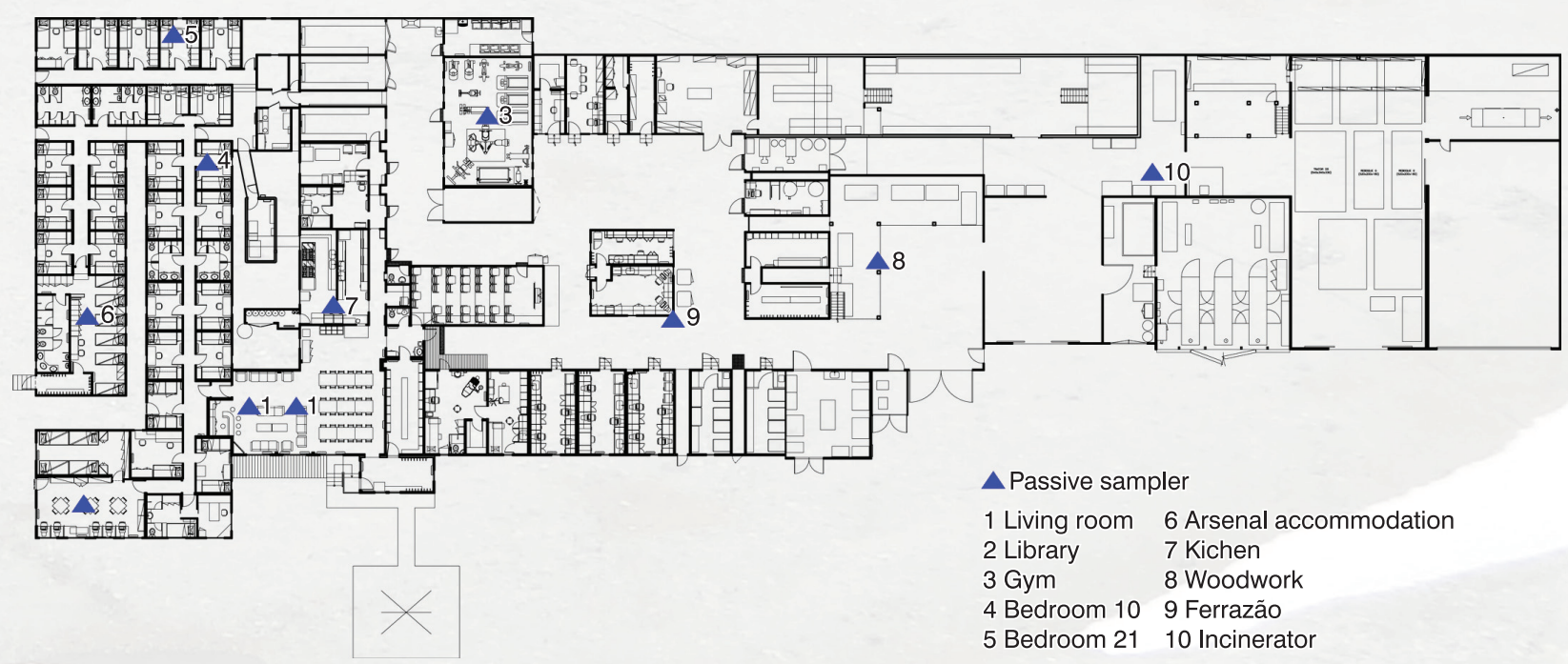

Figure 1. Floor map of the Brazilian Antarctic Station showing the sites of aldehydes passive samplers. 
filtered and stored in vials, below $4{ }^{\circ} \mathrm{C}$, awaiting analysis (Fondazione Salvatore Maugeri, 2011).

Sampler analyses were performed by reverse-phase High Performance Liquid Chromatography (HPLC) using an UV detector operated at a wavelength of $365 \mathrm{~nm}$. The hydrazone separation was carried out on Agilent Technologies C18 column $(250 \times 4.6 \mathrm{~mm}, 5 \mu \mathrm{m})$ associated with a precolumn. Two solutions were used for gradient elution: solution A contained water and solution B contained acetonitrila. Starting conditions: $40 \%$ of solution A and $60 \%$ of solution $B$ for seven minutes, then a linear gradient was applied over 20 minutes with $100 \%$ of solution B. After, between 21 and 30 minutes $40 \%$ of solution $\mathrm{A}$ and $60 \%$ of solution $\mathrm{B}$ were applied again. The eluent flowing rate was $2.0 \mathrm{~mL} / \mathrm{min}$, the temperature was constant in $37^{\circ} \mathrm{C}$ (Collins, 2007, modify).

The determination of the carbonyls was done according to the Environment Protect Agency methodology (EPA, 1999). The aldehydes quantification was done using a standard hydrazone solution TO11/IP-6A (cod. 47285U - Supelco, Bellefonte PA, USA). Both detection and quantification limits were calculated for all samplers according to the guide for validation of analytical and bioanalytical methods (ANVISA, 2003).

\section{Results}

Figure 3 shows the aldehydes concentration found for each sampler place. The average concentration of total indoor air carbonyls was $196.06 \mu \mathrm{g} / \mathrm{m}^{3}$. The acrolein was the most abundant carbonyls in most air samples, followed by acetaldehyde, formaldehyde, hexanaldehyde, butyraldehyde, pentanaldehyde, isopentanaldehyde, propinaldehyde and benzaldehyde with the average value of respectively $44.41 \mu \mathrm{g} / \mathrm{m}^{3} ; 38.33 \mu \mathrm{g} / \mathrm{m}^{3} ; 33.68 \mu \mathrm{g} / \mathrm{m}^{3} ; 30.88 \mu \mathrm{g} / \mathrm{m}^{3}$; $21.80 \mu \mathrm{g} / \mathrm{m}^{3} ; 9.01 \mu \mathrm{g} / \mathrm{m}^{3} ; 8.45 \mu \mathrm{g} / \mathrm{m}^{3} ; 8.30 \mu \mathrm{g} / \mathrm{m}^{3}$ and $1.21 \mu \mathrm{g} / \mathrm{m}^{3}$. Acrolein, acetaldehyde, formaldehyde and hexanaldehyde accounted for respectively $22 \%, 20 \%, 17 \%$ and $16 \%$ of total aldehydes indoor air.

The acetaldehyde concentration was higher in the living room $\left(70.02 \mu \mathrm{gm}^{3} ; 81.28 \mu \mathrm{g} / \mathrm{m}^{3} ; 58.13 \mu \mathrm{g} / \mathrm{m}^{3}\right)$ and kitchen $\left(70.63 \mu \mathrm{g} / \mathrm{m}^{3} ; 80.22 \mu \mathrm{g} / \mathrm{m}^{3} ; 108.86 \mu \mathrm{g} / \mathrm{m}^{3}\right)$ than other places. The formaldehyde concentration was higher in the bedrooms $\left(100.93 \mu \mathrm{g} / \mathrm{m}^{3}\right.$ for bedroom 10 and $131.67 \mu \mathrm{g} / \mathrm{m}^{3}$ for bedroom 21 ). Bedroom 21 had a significant concentration of hexanaldehyde too $\left(97.52 \mu \mathrm{g} / \mathrm{m}^{3}\right)$ contrary to the concentration for bedroom $10\left(13.58 \mu \mathrm{g} / \mathrm{m}^{3}\right)$. In the library the main compounds found were: acrolein $\left(61.84 \mu \mathrm{g} / \mathrm{m}^{3} ; 58.54 \mu \mathrm{g} / \mathrm{m}^{3}\right)$, formaldehyde $\left(36.10 \mu \mathrm{g} / \mathrm{m}^{3}\right.$; $\left.39.48 \mu \mathrm{g} / \mathrm{m}^{3}\right)$, acetaldehyde $\left(20.66 \mu \mathrm{g} / \mathrm{m}^{3} ; 24.1152 / \mathrm{m}^{3}\right)$ and hexanaldehyde $\left(18.76 \mu \mathrm{g} / \mathrm{m}^{3} ; 19.11 \mu \mathrm{g} / \mathrm{m}^{3}\right)$.

The least concentration from all the compounds was found in the gym, "Ferrazão", carpentry and incinerator. The concentration of propinaldehyde and benzaldehyde was found in minor importance, similar to the concentration found by Clarisse et al. (2003).
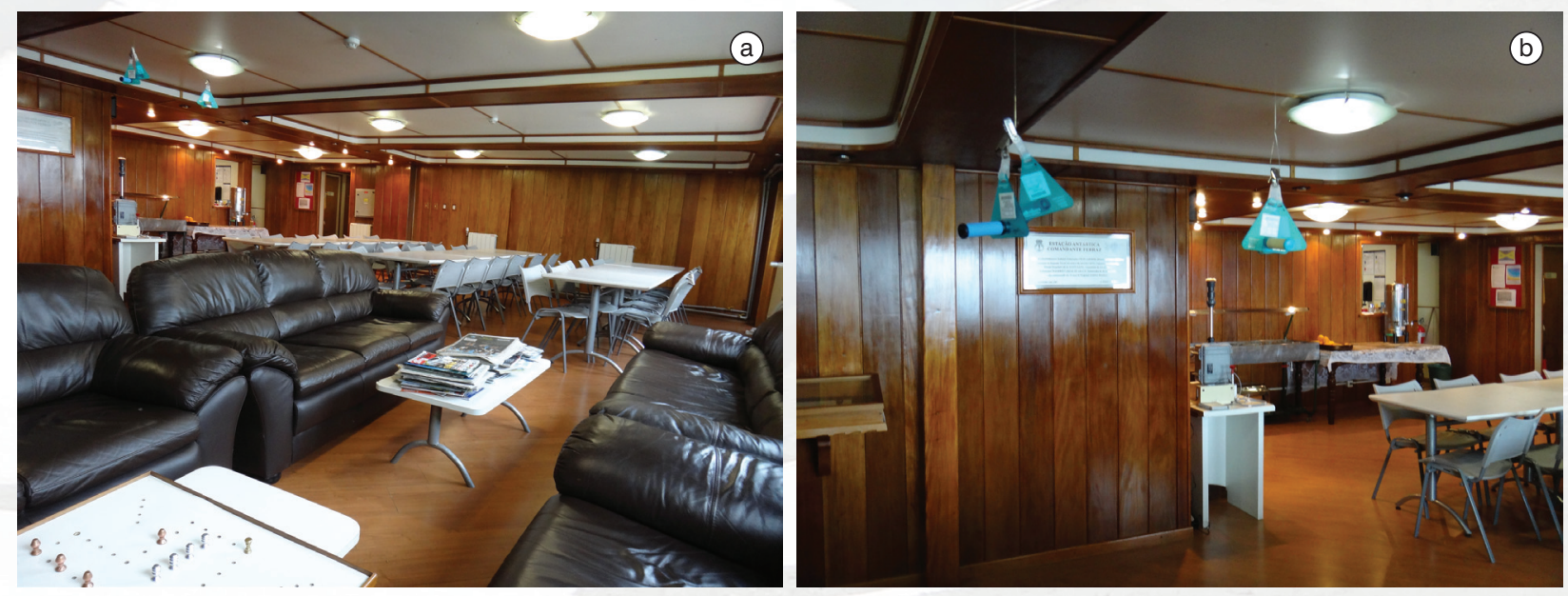

Figure 2. $a$ and b): Passive samplers located $1,5 \mathrm{~m}$ high in the living room 


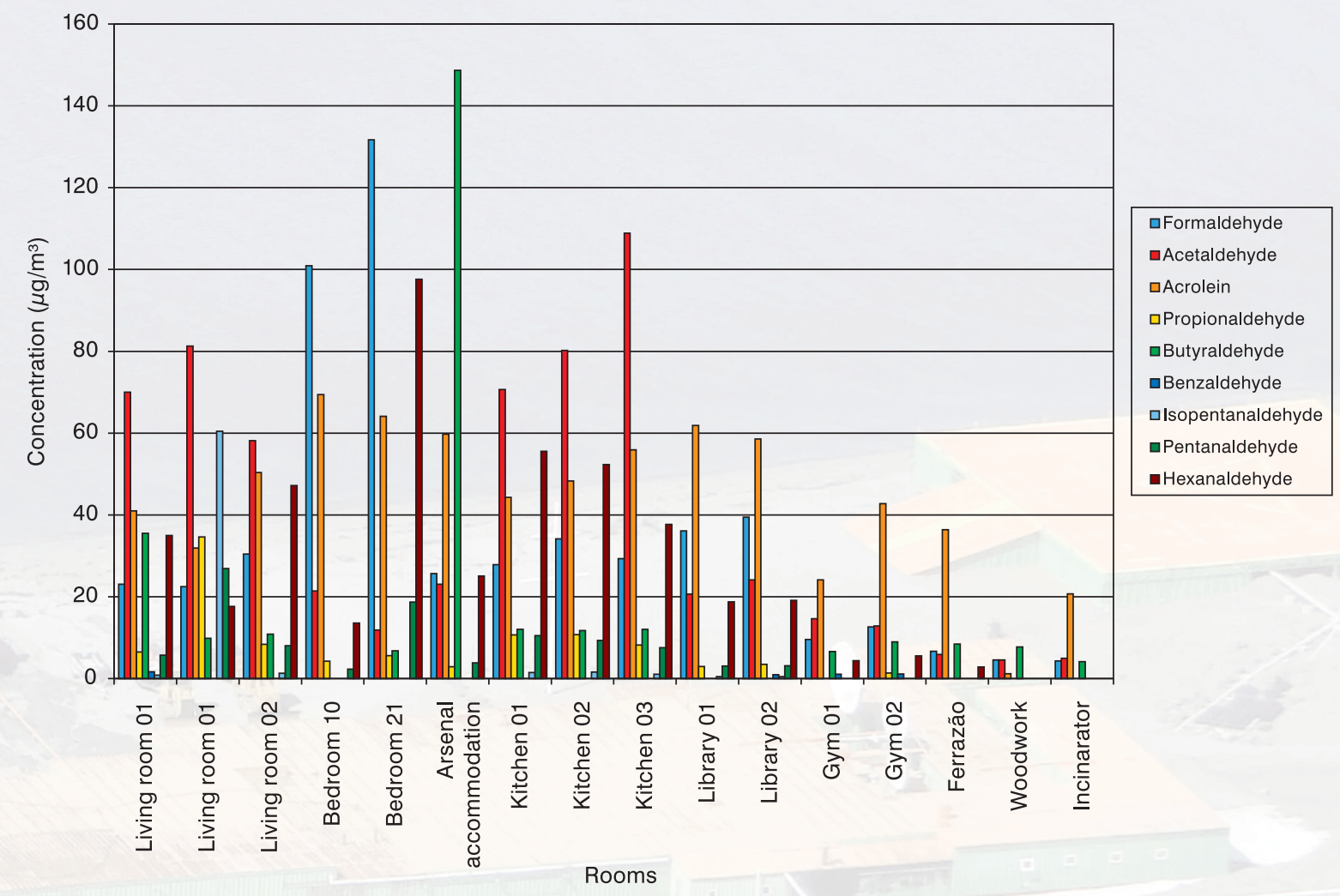

Figure 3. Concentration of indoor air aldehydes in the Comandante Ferraz Antarctic Station rooms.

\section{Discussion}

Levels of acrolein, acetaldehyde and formaldehyde are the most studied in relation to indoor air quality (Andrade et al., 2002). Studies related to heated cooking oils produce considerable amounts of acrolein. Cooking is an important source of indoor acrolein. In addition it is also formed by the oxidation of voltatic organic carbon species released by building materials (Seaman et al., 2009). The abundant concentration of acrolein found in the cartridges in our work can be explained by the activity of frying in a closed building like the Antarctic Station. Some spaces like living room and kitchen sometimes have open windows but the bedrooms and the library were closed most of the time resulting in higher concentration.

There are three main sources of acetaldehyde: cleaning agents, people and building materials. The higher acetaldehyde concentration in the kitchen and living room can be related to a constant use of cleaning agents in this place. In the Brazilian Antarctic Station the living room and kitchen are cleaned about four times a day. Moreover these rooms have a large number of people during breakfast, lunch, dinner and parties. Andrade et al. (2002) stated that the main source of acetaldehyde in human organism is the metabolism of ethanol. Part of this concentration can also result from wood products such as doors, walls and plywood floor (Marchand et al., 2005) found in the living room of the station.

Many studies reported that formaldehyde is released by various building materials mainly wood-pressed products and the levels are significantly greater in new buildings (Missia et al., 2010). The rooms that had the highest concentration for formaldehyde were the bedrooms. The highest concentration was found in bedroom 21 probably because it is one of the most recently built bedrooms of the station. It was first utilized in this campaign. There was laminated wood flooring and composite-wood furnishings. Bedroom 10 had the same building materials but it was older, although this bedroom showed significant levels of 
formaldehyde concentration too. Despite many studies associated VOCs concentration in new buildings, little is known about the behavior of these indoor compounds after a certain period of time (Clarisse et al., 2003).

It is important to note that the formaldehyde concentration in bedroom 21 for an exposure of seven days was greater than the limit of the World Health Organization, which is $100 \mu \mathrm{g} / \mathrm{m}^{3}$ for 30 minutes exposition. Lower values were found in other studies. Missia et al. (2010) found 5.8-62.6 $\mu \mathrm{g} / \mathrm{m}^{3}$ inside three buildings with different ages and different ventilation systems and Weng et al. (2009) found a mean concentration for formaldehyde of $90.61 \mu \mathrm{g} /$ $\mathrm{m}^{3}$ inside supermarkets, stores and cinemas.

Bedroom 21 showed the highest hexanaldehyde concentration compared to bedroom 10 , which had the same building materials. This is due to the new plywood sub floor in bedroom 21, which is a probable major hexanal source, this compound is observed in abundance in new spaces with less than two years of construction using this material (Marchand et al., 2005). The library showed significant levels of formaldehyde and acetaldehyde. A variety of VOCs are known to be emitted from paper and other cellulose-based materials during degradation, this includes the aldehydes as formaldehyde and acetaldehyde (Fenech et al., 2010).

The least concentration of aldehydes was shown in the places with greater air exchange, such as the gym, where the windows are frequently opened, and also in "Ferrazão", carpentry and incinerator that are located outside the main body of the station.

\section{Conclusion}

Compounds such as acrolein, formaldehyde, acetaldehyde and hexanaldehyde make a significant contribution to indoor air quality. Regarding building material, it is very likely that the pressed wood used in the floor, walls and furnishing present in the Antarctic Brazilian Station are responsible for many emissions of these pollutants. The formaldehyde, that is dangerous to health, showed higher levels in bedrooms mainly the new bedroom. Furthermore, the human activities such as cooking and cleaning agents were also responsible for some of the compounds detected. This may indicate the need to review the building materials and indoor ventilation strategy, as an important instrument of control of the sources of pollutant emissions.

\section{Acknowledgements}

This work integrates the National Institute of Science and Technology Antarctic Environmental Research (INCTAPA) that receives scientific and financial support from the National Council for Research and Development (CNPq process: $n^{\circ}$ 574018/2008-5) and Carlos Chagas Research Support Foundation of the State of Rio de Janeiro (FAPERJ $\left.\mathrm{n}^{\circ} \mathrm{E}-16 / 170.023 / 2008\right)$. The authors also acknowledge the support of the Brazilian Ministries of Science, Technology and Innovation (MCTI), of Environment (MMA) and InterMinistry Commission for Sea Resources (CIRM).

\section{References}

Agência Nacional De Vigilância Sanitária - ANVISA. (2003). Resolução nº 899, de 29 de maio de 2003. Diário Oficial da República Federativa do Brasil, Brasília, maio.

Andrade, M.A.S.; Pinheiro, H.L.C.; Pereira, P. \& Andrade, J. (2002). Compostos carbonílicos atmosféricos. Química nova, 25(6): 1117-1131.

Clarisse, B.; Laurent, A.M.; Seta, N.; Moullec, Y.; Le; Hasnaoui, A.E. \& Momas, I. (2003). Indoor aldehydes: measurement of contamination levels and of their in Paris dwellings. Atmospheric Environment, 92(3): 245-53.

Collins, C.H.; Braga, G.L. \& Bonato, P.S. (2007). Fundamentos de cromatografia. São Paulo: Ed. Unicamp. 453 p.

European Standard. (2006). EN ISO 16000-1: Indoor air: general aspects of sampling strategy. Bruxelas. 
Fenech, A.; Strlic, M.; Cigic, I.; Levart, A.; Gibson, L.; Bruin, G.; Ntanos, K.; Kolar, J. \& Cassar, M. (2010). Volatile aldehydes in libraries and archives. Atmospheric Environment, 92(3): 245-53.

Fondazione Salvatore Maugeri (2011). Manual Radiello. Ed. Supelco.

Marchand, C.; Bulliot, B.; Calve, S.; Mirabel, P. Aldehyde measurements in indoor environments in Strasbourg - France. (2005). Atmospheric Environment, 40(7): 1336-1345.

Missia, D.; Demetriou, E.; Michael, N.; Tolis, E.I. \& Bartzis, J.G. (2010). Indoor exposure from building materials: a field study. Atmospheric Environment, 44(35): 4388-4395.

Seaman, V.; Bennett, D.; Cahill, T. (2009). Indoor acrolein emission and decay rates resulting from domestic cooking events. Atmospheric Environment, 43(39): 6199-6204.

U.S. Environmental Protection Agency - EPA. (1999). TO-11A: Determination of Formaldehyde in Ambient Air Using Adsorbent Cartridge Followed by HPLC.USA

Weng, M.; Zhu, L.; Yang, K. \& Chen, S. (2009). Levels and health risks of carbonyl compounds in selected public places in China. Journal of Hazardous Materials, 164(2-3): 700-6.

Weschler, C.J. Changes in indoor pollutants since the 1950s. (2008). Atmospheric Environment, 43(1): 153-169.

World Health Organization - WHO. (2010). Guidelines for indoor air quality. Europe. 